\title{
A Study of Clinical Profile of Intracerebral Hemorrhage and ENT Manifestations and its Surgical Outcome
}

\author{
${ }^{1}$ Vishwanath Sidram, ${ }^{2}$ PC Chandra Kumar, ${ }^{3}$ Bellara Raghavendra
}

\begin{abstract}
Introduction: The aim of this study is to study the clinical profile and outcome of primary and secondary intracerebral hemorrhage $(\mathrm{ICH})$ and to study the different parameters that affect the outcome.
\end{abstract}

\begin{abstract}
Materials and methods: A total of 40 patients who were diagnosed to have $\mathrm{ICH}$, both primary and secondary, by computed tomography scan were included in the study. Among the selected patients, the clinical profile, radiological profile, and the modality of treatment undertaken and the outcome were noted. Outcome variables included survived [improvement in the Glasgow Coma Scale (GCS)], death, and vegetative state. The outcome variable was compared with respect to age, sex, GCS, etiology, location of the hematoma, and the modality of treatment to find out any statistically significant difference in the rate of outcomes.
\end{abstract}

Results: The mean age of the patients was $36.78 \pm 18.5$ years; mean GCS at the time of presentation was $9.05 \pm 1.82$. Common causes of ICH were trauma (57.5\%) and hypertension (25\%). Significant association was found between outcome and age group, GCS, etiology of $\mathrm{ICH}$, and location of the bleed. Poor outcome was associated with GCS $\leq 8(40 \%),>50$ years of age $(45.5 \%)$, hypertension (50\%), and basal ganglia bleed $(50 \%)$. Best outcome was seen in patients with GCS $\geq 9$, a lobar bleed, and trauma as the cause of $\mathrm{ICH}$ where the patient survival was $90 \%$.

Conclusion: In case of $\mathrm{ICH}$ depending upon the clinical and radiological profile, the treatment should be individualized. The rates of survival and favorable outcome are better in patients with GCS $\geq 9$, a lobar bleed, and trauma as the cause of $\mathrm{ICH}$.

Keywords: Glasgow coma scale, Hypertension, Intracerebral hemorrhage, Trauma.

How to cite this article: Sidram V, Kumar PCC, Raghavendra B. A Study of Clinical Profile of Intracerebral Hemorrhage and ENT Manifestations and its Surgical Outcome. Int J Head Neck Surg 2017;8(1):5-10.

\footnotetext{
${ }^{1}$ Professor, ${ }^{2,3}$ Associate Professor

${ }^{1}$ Department of Neurosurgery, Vijayanagar Institute of Medical Sciences, Bellary, Karnataka, India

${ }^{2}$ Department of General Surgery, Vijayanagar Institute of Medical Sciences, Bellary, Karnataka, India

${ }^{3}$ Department of Community Medicine, Vijayanagar Institute of Medical Sciences, Bellary, Karnataka, India

Corresponding Author: Vishwanath Sidram, Professor Department of Neurosurgery, Vijayanagar Institute of Medical Sciences, Bellary, Karnataka, India, Phone: +919019163674 e-mail: vsidram@gmail.com
}

\section{Source of support: Nil}

Conflict of interest: None

\section{INTRODUCTION}

The reported incidence of asymptomatic and symptomatic intracranial hemorrhage varies from study to study. However, the incidence of intracerebral hemorrhage (ICH) varies from 11 to 23 cases per 100,000 per year and it accounts for only 10 to $15 \%$ of all strokes. It is the most fatal stroke subtype with a mortality up to $40 \%{ }^{1}$ Intracerebral hemorrhage is more common than subarachnoid hemorrhage (SAH) and is much more likely to result in death or major disability than cerebral infarction or $\mathrm{SAH}{ }^{2}$ More than $50 \%$ of the patients die and nearly half of the survivors are left severely disabled state, with significant personal, social, and health service costs. ${ }^{3}$

Anatomically, ICH can be classified as parenchymatous, subarachnoid, subdural, epidural, supra and infratentorial hemorrhages, and etiologically it can be classified as primary or spontaneous hemorrhages and secondary hemorrhages. Primary hemorrhages are spontaneous hemorrhages, which are mainly caused by arterial hypertensive diseases. Secondary hemorrhages are due to traumatic, tumorous, or pharmacological causes. ${ }^{4}$

The precise role of surgical intervention in the management of ICH is still debatable; however, in clinical practice, the indications of surgical intervention are uncertain $^{3,5}$ and depend on presenting Glasgow coma scale (GCS), size, and location of the ICH, which in turn are believed to effect the outcome after surgical removal of the ICH. ${ }^{6,7}$

The aim of this study was to study the clinical profile and outcome of $\mathrm{ICH}$, both primary and secondary, after surgical evacuation and conservative treatment of $\mathrm{ICH}$, and to study the different parameters that affect the outcome.

\section{MATERIALS AND METHODS}

The study was done in the setting of tertiary hospital, Department of Neurosurgery at Vijayanagar Institute of Medical Sciences (VIMS), Bellary, Karnataka, India, during the period of June 2013 to January 2015. A total of 40 patients who were diagnosed to have $\mathrm{ICH}$, both primary and secondary, by computed tomography scan 
were included in the study. Depending on the size, location, and etiology of hematoma, some of the patients were treated by surgical evacuation of the hematoma, excision of the tumor, and other patients were treated conservatively. Among the selected patients, the clinical profile, operative details, and the surgical interventions were undertaken and the outcome was noted. All patients were followed for 3 months to assess the clinical outcome.

Clinical variables included age at the time of presentation, sex, etiology, location of the hematoma, and the GCS scoring. Outcome variables included survived (improvement in the GCS), death, and vegetative state or severely disabled. The outcome variable was compared with respect to age, sex, GCS, etiology, location of the hematoma, and the modality of treatment to find out any statistically significant difference in the rate of outcomes.

\section{Statistical Analysis}

All the collected data variables were entered into an excel sheet and later transferred to and analyzed using Statistical Package for the Social Sciences software version 22. Appropriate descriptive statistics like percentages/ proportions were used to describe the data variables. Appropriate tests of significance were applied to know the difference in the rate of outcomes between the groups (chi-square test, Fisher's exact test), and p-value $<0.05$ was considered significant.

The study was given ethical approval by Ethical Review Committee of VIMS. All ethical requirements including confidentiality of identity, responses, and informed consent were stringently ensured throughout the project.

\section{RESULTS}

A total of 40 patients were included in the study, wherein both male (52.5\%) and female (47.5\%) patients were almost equally distributed. The mean age of the patients was 36.78 years, with a standard deviation of 18.5 years. Half of the patients were in the age group of 20 to 50 years, a little over one-fifth of them were aged $<20$ years $(22.5 \%)$, and nearly one-third of the patients were aged $>50$ years (27.5\%) (Table 1).

Among the symptomatology, altered sensorium $(42.5 \%)$, headache $(37.5 \%)$, convulsions $(30 \%)$, and vomiting $(20 \%)$ were the main presenting symptoms. Other symptoms included nausea $(10 \%)$ and other neurological findings that included hemiparesis $(12.5 \%)$, focal neurological deficits (12.5\%), quadriparesis $(2.5 \%)$, and aphasia $(2.5 \%)$. The mean GCS of the patients at the time of admission was $9.05 \pm 1.82$, wherein $37.5 \%$ of the patients had GCS of less than 9, half of them had GCS of 9 to 12, and $10 \%$ of the patients had normal GCS (Table 2).
Table 1: Age and sex-wise distribution of the patients

\begin{tabular}{lll}
\hline Variable & Frequency & Percentage \\
\hline Sex & & \\
Male & 21 & 52.5 \\
Female & 19 & 47.5 \\
Total & 40 & 100 \\
Age group & & \\
$<20$ yrs & 9 & 22.5 \\
$20-50$ yrs & 20 & 50.0 \\
$>50$ yrs & 11 & 27.5 \\
Total & 40 & 100 \\
Mean age \pm SD (in years) & $36.78 \pm 18.59$ & \\
\hline
\end{tabular}

SD: Standard deviation

Table 2: Clinical profile of the patients $(n=40)$

\begin{tabular}{lll}
\hline Variable & Frequency & Percentage \\
\hline Symptoms & & \\
Altered sensorium & 17 & 42.5 \\
Headache & 15 & 37.5 \\
Seizures & 12 & 30.0 \\
Vomiting & 8 & 20.0 \\
Nausea & 4 & 10.0 \\
Hemiparesis & 5 & 12.5 \\
Focal neurological deficits & 5 & 12.5 \\
Quadriparesis & 1 & 2.5 \\
Aphasia & 1 & 2.5 \\
GCS & & \\
$<9$ & 15 & 37.5 \\
9-12 & 21 & 52.5 \\
13-15 & 4 & 10.0 \\
Mean GCS \pm SD & $9.05 \pm 1.82$ & \\
\hline
\end{tabular}

*Multiple symptoms

Trauma was the most common cause of $\mathrm{ICH}$, causing hemorrhage in 23 patients ( $57.5 \%$ ), followed by hypertension in 10 cases $(25 \%)$, bleeding diathesis in 4 cases $(10 \%)$, and intracranial tumor in 3 cases $(7.5 \%)$ ( 1 case of parasagittal meningioma and posterior fossa medulloblastoma). Four cases of bleeding diathesis included 2 cases of idiopathic thrombocytopenic purpura and 2 cases with hemophilia. In 3 cases of idiopathic thrombocytopenic purpura, the bleeding was probably due to decrease in platelet count. Severe factor VIII deficiency was the incriminated factor for ICH in hemophilics (Table 3).

Computed tomography was performed in all our patients and magnetic resonance imaging in 13 patients. The location of hemorrhage was supratentorial in 31 patients $(77.5 \%)$ and infratentorial in 9 patients (2022.5\%) (2 brainstem hematoma and 7 cerebellar hematomas). In supratentorial hematomas, the most common location was lobar in 23 patients (Figs 1 and 2), putamenal in 4 patients, thalamic in 2 patients, and 2 cases with a caudate hematoma (Fig. 3; Table 4). Intraventricular hemorrhage was associated in 3 of our patients. 
A Study of Clinical Profile of Intracerebral Hemorrhage and ENT Manifestations and its Surgical Outcome

\begin{tabular}{llc}
\hline \multicolumn{2}{c}{ Table 3: Etiological profile of the patients $(\mathrm{n}=40)$} \\
\hline Variable & Frequency & Percentage \\
\hline Trauma & 12 & 30.0 \\
Road traffic accident & 11 & 27.5 \\
Assault & & \\
Hypertension & 10 & 25.0 \\
Essential hypertension & & \\
Bleeding diathesis & 2 & 5.0 \\
Hemophilia & 2 & 5.0 \\
Idiopathic thrombocytopenic purpura & 2.5 \\
Tumor & 1 & \\
Parasagittal meningioma & 2 & 5.0 \\
Posterior fossa medulloblastoma & 2 & \\
\hline
\end{tabular}

The treatment was individualized based on the clinical profile, the etiological factor, and the radiological findings. Eleven patients were treated conservatively in whom there were no signs of raised intracranial pressure (ICP), with GCS $\geq 12$, small bleed, which had bleeding diathesis and hypertensive bleed located at putamen, caudate, and cerebellar regions. The conservative treatment consisted

\begin{tabular}{lll}
\multicolumn{3}{c}{ Table 4: Radiological profile of the patients $(\mathrm{n}=40)$} \\
\hline Location & Frequency & Percentage \\
\hline Supratentorial & 31 & 77.5 \\
Lobar & 23 & 57.5 \\
Putamenal & 4 & 10.0 \\
Thalamic & 2 & 5.0 \\
Caudate & 2 & 5.0 \\
Infratentorial & 9 & 22.5 \\
Cerebellar & 7 & 17.5 \\
Brainstem & 2 & 5.0 \\
\hline
\end{tabular}

of care of the general condition (airway, breathing, and circulation), control of the ICP, antiepileptic measures, as well as correction of the underlying coagulation problem. Twenty-nine patients were treated surgically and consisted of hematoma evacuation via craniotomy (Fig. 4) and tumor excision in 3 patients. Two patients required an external ventricular drain and 1 patient required a permanent ventriculoperitoneal shunt. The average length of hospital stay was 18 days.

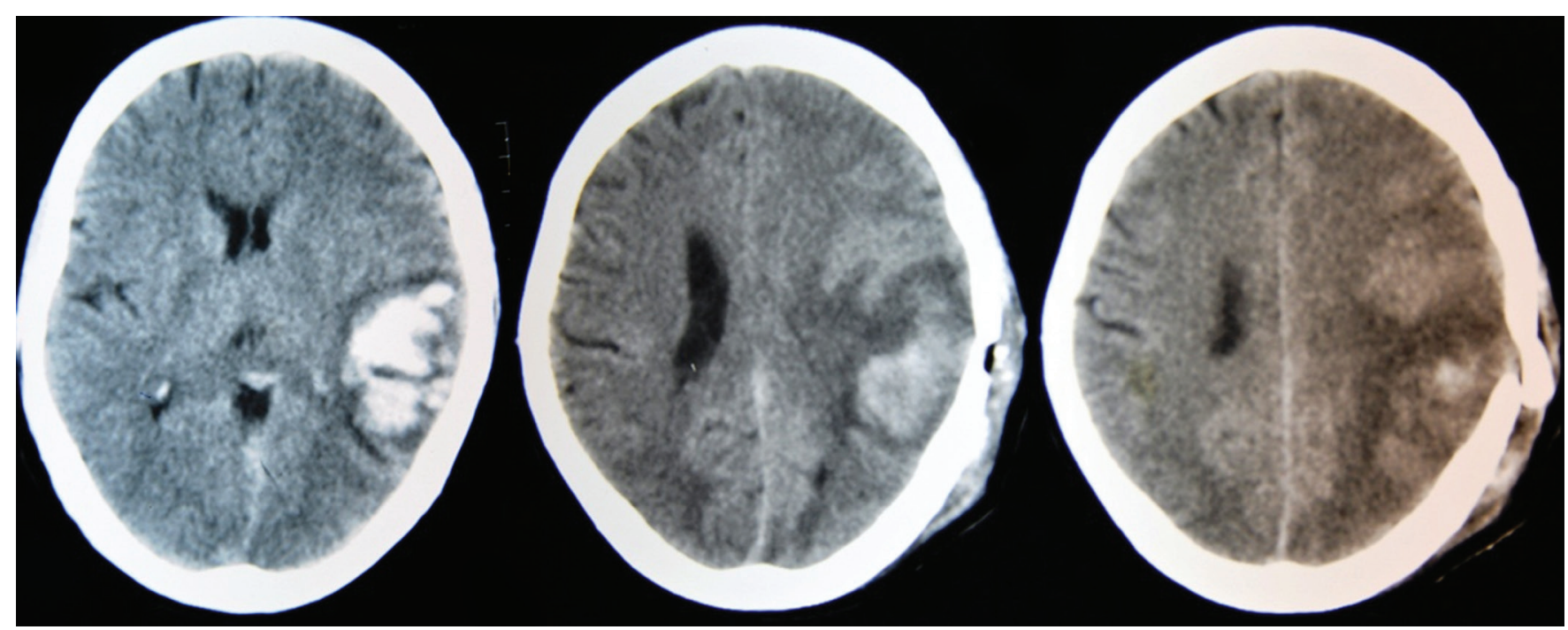

Fig. 1: Computed tomography brain image showing left parieto-occipital $\mathrm{ICH}$. Postoperative $\mathrm{CT}$ brain image showing partial and complete resolution of $\mathrm{ICH}$ in same patient in subsequent follow-up period

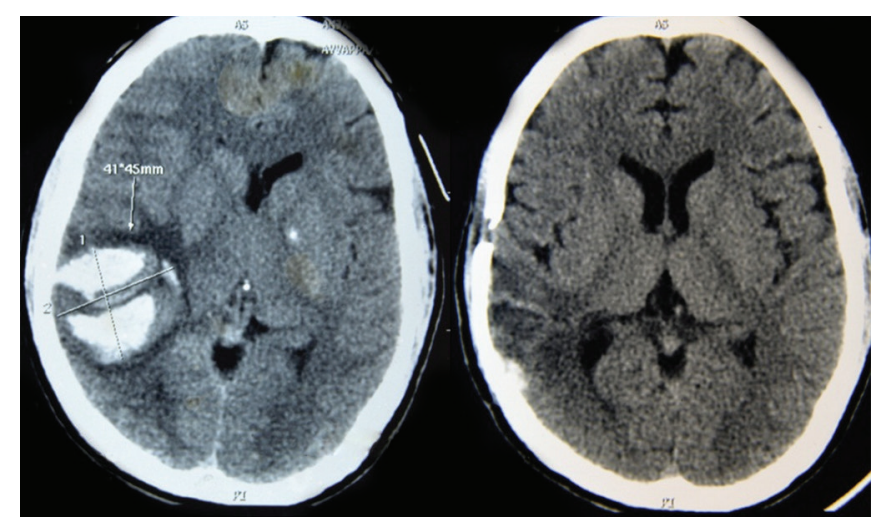

Fig. 2: Computed tomography brain image showing right parietooccipital ICH with midline shift and postoperative CT brain image showing resolution of $\mathrm{ICH}$ in the same patient

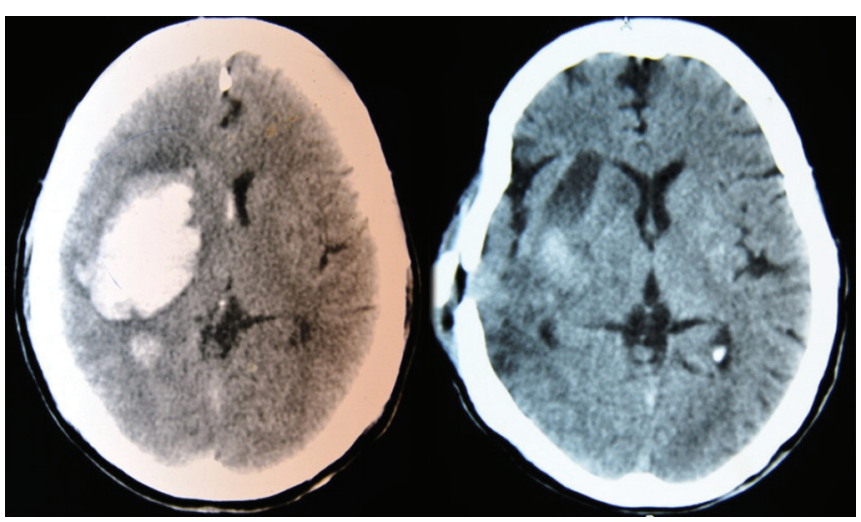

Fig. 3: Computed tomography brain image showing hypertensive bleed in basal ganglia region. Postoperative CT brain image showing resolution in the same patient 


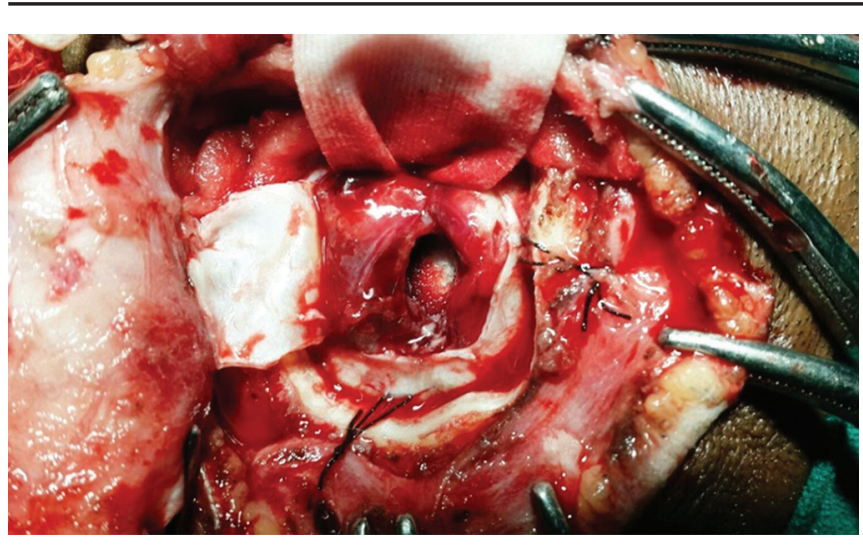

Fig. 4: Intraoperative image after evacuation of $\mathrm{ICH}$

Table 5: Outcome of the management of the patients

\begin{tabular}{lll}
\hline Outcome & Frequency & Percentage \\
\hline Death & 6 & 15.0 \\
Vegetative state & 2 & 5.0 \\
Survived/improved & 32 & 80.0 \\
\hline Total & 40 & 100 \\
\hline
\end{tabular}

The outcome of the patients was classified as survived or improved (showed improvement in the GCS), vegetative state, and death. In our series, the outcome of our patients was as follows: Survived or improved in $32(80 \%)$, vegetative state in 2 (5\%), and death in 6 (15\%) (Table 5).

The proportion of poor outcome (death and vegetative state) was more in patients who were $>50$ years $(45.5 \%)$ and with GCS $<9(40 \%)$ compared with rest of the age groups and GCS $>9$, and this association was found to be statistically significant. There was statistically significant association between poor outcome and precipitating cause (etiology) and the location of the bleed wherein the rate of poor outcome was more in patients with hypertensive bleed (50\%), intracranial tumor (30\%), bleeding in thalamic (100\%), caudate (50\%), and brainstem (50\%) regions. However, there was no statistically significant difference in the outcome with respect to modality of treatment and gender of the patient (Table 6).

\section{DISCUSSION}

In the present series, a total of 40 patients diagnosed with $\mathrm{ICH}$, both spontaneous (primary) (14 cases) and secondary (26 cases), were studied (Table 3 ). The mean age of the patients was $36.78 \pm 18.59$ years. Altered sensorium $(42.5 \%)$, headache $(37.5 \%)$, convulsions $(30 \%)$, and vomiting $(20 \%)$ were the main presenting symptoms, which are in consonance with other studies, and mean GCS of the patients was $9.05 \pm 1.82$ at the time of presentation. ${ }^{8,9}$

Trauma was the most common cause of $\mathrm{ICH}$ in our study, which is in consonance with the study done by Zidan and Ghanem ${ }^{8}$ and the second most common cause was hypertensive bleed. Arterial hypertension is
Table 6: Outcome of the patients with respect to clinical variables

\begin{tabular}{|c|c|c|c|}
\hline Variables & $\begin{array}{l}\text { Death/ } \\
\text { vegetative } \\
\text { state } n(\%)^{*}\end{array}$ & $\begin{array}{l}\text { Survived } \\
\text { improved } \\
n(\%)^{*}\end{array}$ & $p$-value \\
\hline \multicolumn{4}{|l|}{ Age group } \\
\hline$<20$ yrs $(n=9)$ & $1(11.1)$ & $8(88.9)$ & 0.026 \\
\hline $20-50$ yrs $(n=20)$ & $2(10.0)$ & $18(90.0)$ & \\
\hline$>50$ yrs $(n=11)$ & $5(45.5)$ & $6(54.5)$ & \\
\hline \multicolumn{4}{|l|}{ Sex } \\
\hline Male $(n=21)$ & $2(9.5)$ & $19(90.5)$ & \\
\hline Female $(n=19)$ & $6(31.6)$ & $13(68.4)$ & 0.177 \\
\hline \multicolumn{4}{|l|}{ GCS } \\
\hline$<9(n=15)$ & $6(40.0)$ & $9(60.0)$ & 0.043 \\
\hline $9-12(n=25)$ & $2(8.0)$ & $23(92.0)$ & \\
\hline \multicolumn{4}{|l|}{ Etiology grp } \\
\hline Bleeding diathesis $(n=4)$ & $0(0.0)$ & $4(100.0)$ & 0.032 \\
\hline Hypertension $(n=10)$ & $5(50.0)$ & $5(50.0)$ & \\
\hline Trauma $(n=23)$ & $2(8.7)$ & $21(91.3)$ & \\
\hline Tumor $(n=3)$ & $1(33.3)$ & $2(66.7)$ & \\
\hline \multicolumn{4}{|l|}{ Location } \\
\hline Infratentorial $(n=9)$ & $2(22.2)$ & $7(77.8)$ & 0.834 \\
\hline Supratentorial $(n=31)$ & $6(19.4)$ & $25(80.6)$ & \\
\hline \multicolumn{4}{|l|}{ Part involved } \\
\hline Brainstem $(n=2)$ & $1(50.0)$ & $1(50.0)$ & 0.029 \\
\hline Cerebellar $(n=7)$ & $1(14.3)$ & $6(85.7)$ & \\
\hline Lobar $(n=23)$ & $2(8.7)$ & $21(91.3)$ & \\
\hline Putamenal $(n=4)$ & $1(25.0)$ & $3(75.0)$ & \\
\hline Thalamic $(n=2)$ & $2(100.0)$ & $0(0.0)$ & \\
\hline Caudate $(n=2)$ & $1(50.0)$ & $1(50.0)$ & \\
\hline \multicolumn{4}{|l|}{ Treatment } \\
\hline Conservative $(n=11)$ & $2(18.2)$ & $9(81.8)$ & 0.897 \\
\hline Surgical intervention** $(n=29)$ & $6(20.7)$ & $25(86.2)$ & \\
\hline Total & $8(20.0)$ & $32(80.0)$ & \\
\hline
\end{tabular}

*Numbers in the parenthesis are row percentages; ${ }^{* *}$ surgical intervention included hematoma evacuation via craniotomy and tumor excision in three patients

the common cause in most of the primary ICHs (in up to $90 \%$ of patients). ${ }^{4}$

Trauma being the common cause of ICH in our study, the commonest location of $\mathrm{ICH}$ was lobar region and among hypertensive bleeds the common location was putamen, caudate, and thalamus. The localization of the hematoma is associated with the etiology of hemorrhage. Hypertensive hemorrhages frequently involve basal ganglia, thalamus, or the posterior fossa. The primary hemorrhages based on amyloid angiopathy may result in lobar hematomas, typically at the border of the gray and white matter. But cerebral amyloid angiopathy-associated hemorrhages can also involve the subarachnoidal space or result in cerebellar hematomas. ${ }^{10,11}$

Depending upon clinical and radiological profile of the patients, 11 patients $(27.5 \%)$ underwent conservative treatment and 29 patients (72.5\%) underwent surgical intervention, which involved hematoma evacuation via craniotomy and tumor excision in 3 patients. Patients 
with no signs of raised ICP, with GCS more than 12 , small bleeds, patients with bleeding diathesis, and hypertensive bleeds with GCS less than 8 were treated conservatively.

There is difference of opinion about the role of surgical intervention in the management of $\mathrm{ICH}$, whether $\mathrm{ICH}$ should be evacuated surgically. However, the prognosis of patients with $\mathrm{ICH}$ remains poor, independently of whether they are surgically treated or not. The mortality among patients with ICH is high up to $50 \%$, and many patients surviving ICH remain in a severe vegetative state. Thus, the outcome of a large part of patients is still unsatisfactory. Multiple attempts have failed to find objective criteria to decide whether surgery is useful. ${ }^{4}$

Many studies have been done to know the role of medical and surgical intervention in management of ICH. A study by Juvela et $\mathrm{al}^{12}$ did not find any statistically significant difference in the poor outcome between surgically treated patients (96\%) and conservatively treated patient group (81\%). However, in a study done by Auer et $\mathrm{al}_{1}^{13}$ better outcome was found for patients who were treated surgically, with 28 (56\%) of the 50 patients having a poor outcome, as compared with 37 (74\%) of the 50 managed conservatively having a poor outcome. Multiple studies have since then shown equivocal results, and there is no convincing evidence of benefit from any medical treatment, and the role of surgery remains controversial. 2,3,5,14-16

But most of these studies included only cases of spontaneous bleed and in our study both spontaneous bleed and secondary ICH cases were included. The overall poor outcome (death/vegetative state) was $20 \%$ in our study, which is better compared with above-mentioned studies. In our study, we did not find any statistically significant difference in the poor outcome with respect to modality of treatment. However, statistically significant difference in the poor outcome of patients with GCS $\leq 8$ was $40 \%$ compared with poor outcome of $8 \%$ for patients with GCS $\geq 9$. Best outcome was seen in patients with GCS $\geq 9$, lobar bleed and trauma as the cause of $\mathrm{ICH}$, where the patient survival was $90 \%$. This relation between outcome and the GCS, location of bleed was comparable with other studies done by Singh et al, ${ }^{17}$ Altaf and Vohra, ${ }^{9}$ and Raihan et al. ${ }^{18}$ However, the rate of poor outcome in our study differed with other studies because of the difference in clinical and radiological profile, and treatment was individualized based on the GCS, etiology of ICH, radiological profile of the patients.

To answer the ambiguity in the management of $\mathrm{ICH}$, the Surgical Trial in Intracerebral Hemorrhage trial was carried out in 2005. The trial showed that there are no significant differences between surgical and nonsurgical treated groups. A good outcome was observed in $26 \%$ of the surgical und $24 \%$ of the medical treated group. Even the mortality after 6 months was nearly identical: 36 vs $37 \%$ respectively. Furthermore, the trial showed that poor initial GCS (less than 9) is associated with poor outcome, regardless of surgical or nonsurgical treatment. ${ }^{6}$ The indication for surgical treatment in patients with ICH was summarized in a study done by Reichart and Frank, ${ }^{4}$ who concluded that surgical intervention is indicated in patients with ICH with large hematoma in unconscious patients; in putamenal or lobar $\mathrm{ICH}$, the clinical state of the patient should be taken into consideration. If secondary neurological deterioration occurs and the volume of hematoma is 50 to $60 \mathrm{~mL}$, open craniotomy and evacuating of the hematoma could rescue from death. Cerebellar hematomas are a special subtype, showing a good clinical outcome if the initial clinical state is good. In this case, decompression should be done immediately to avoid compression of the brainstem. However, the surgical intervention is advised in cases of large hemorrhages including the brainstem or the thalamus. Conscious patients with hematomas between 30 and $50 \mathrm{~mL}$ should undergo medical treatment, and in old unconscious patients showing signs of affection of the brainstem, the prognosis seems to be hopeless, thus surgery is not advisable.

In a study done by Schwarz et $\mathrm{al}^{15}$ it was found that hematoma evacuation did not improve outcome in supratentorial spontaneous $\mathrm{ICH}$, and their data suggested that the only effect of hematoma evacuation is to stop progressive deterioration rather than to improve overall clinical outcome.

In a study done by Singh et $\mathrm{al}^{17}$ it was found that emergency craniotomy and evacuation of the hematoma could be a feasible option between 40 and $100 \mathrm{~mL}$ of primary supratentorial ICH without intraventricular extension. In cases of intraventricular extension of hematoma, surgery is less helpful. Midline shift of $5 \mathrm{~mm}$ or more might be a poor prognostic factor. In another study done by Raihan et $\mathrm{al}^{18}$ for determination of the potential factors of good outcome in spontaneous intracerebral hematoma (SICH) which could be useful for selecting patients for surgical procedure, it was concluded that good surgical outcome in $\mathrm{SICH}$ can be predicted on admission by volume of hematoma, location of hematoma, and time lapse since ictus to surgery.

\section{CONCLUSION}

Trauma and hypertension bleed are the common causes of $\mathrm{ICH}$, and lobar region is the common location of bleed. In case of $\mathrm{ICH}$, depending on the clinical and radiological profile, the treatment should be individualized. The rates of survival and favorable outcome are better in patients with GCS $\geq 9$, a lobar bleed, and trauma as the cause of ICH. 


\section{ACKNOWLEDGMENTS}

We sincerely thank all the patients and their relatives for their cooperation and support for the smooth conduct of the study. The authors thank all the staff members of the Department of General Surgery, Orthopedics, and Neurosurgery of VIMS, Bellary, for their support. The authors are also grateful to the authors/editors/ publishers of all those articles, journals, and books from where the literature for this article has been reviewed and discussed.

\section{REFERENCES}

1. Kirkman MA, Mahattanakul W, Gregson BA, Mendelow AD. The effect of the result of the STICH trial on the management of spontaneous supratentorial intracerebral haemorrhage in Newcastle. Br J Neurosurg 2008 Dec;22(6):739-746.

2. Broderick JP, Adams HP, Barsan W, Feinberg W, Feldmann E, Grotta J, Kase C, Krieger D, Mayberg M, Tilley B, et al. Guidelines for the management of spontaneous intracerebral hemorrhage. Stroke 1999 Apr;30(4):905-915.

3. Siddique MS, Mendelo AD. Surgical treatment of intracerebral haemorrhage. Br Med Bull 2000;56(2):444-456.

4. Reichart R, Frank S. Intracerebral hemorrhage, indication for surgical treatment and surgical techniques. Open Crit Care Med J 2011 Jan;4:68-71.

5. Hankey GJ, Hon C. Surgery for primary intracerebral hemorrhage: is it safe and effective? A systematic review of case series and randomized trials. Stroke 1997 Nov;28(11):2126-2132.

6. Mendelow AD, Gregson BA, Fernandes HM, Murray GD, Teasdale GM, Hope DT, Karimi A, Shaw MD, Barer DH; STICH investigators. Early surgery versus initial conservative treatment in patients with spontaneous supratentorial intracerebral haematomas in the International Surgical Trial in Intracerebral Haemorrhage (STICH): a randomised trial. Lancet 2005 Jan-Feb;365(9457):387-397.

7. Gregson BA, BroderickJP, Auer LM, Batjer H, Chen XC, JuvelaS, Morgenstern LB, Pantazis GC, Teernstra OP, Wang WZ, et al. Individual patient data subgroup meta-analysis of surgery for spontaneous supratentorial intracerebral hemorrhage. Stroke 2012 Jun;43(6):1496-504.

8. Zidan I, Ghanem A. Intracerebral hemorrhage in children. Alexandria J Med 2012 Jun;48(2):139-145.

9. Altaf I, Vohra AH. Surgical management of spontaneous supratentorial intracerebral hemorrhage. Pak J Neurol Surg 2014;18(1):39-43.

10. Kaufmann, HH. Intracerebral haematomas. New York: Raven Press; 1992.

11. Masuda J, Tanaka K, Ueda K, Omae T. Autopsy study of incidence and distribution of cerebral amyloid angiopathy in Hisayama, Japan. Stroke 1988 Feb;19(2):205-210.

12. Juvela S, Heiskanen O, Poranen A, Valtonen S, Kuurne T, Kaste M, Troupp H. The treatment of spontaneous intracerebral hemorrhage. A prospective randomized trial of surgical and conservative treatment. J Neurosurg 1989 May;70(5):755-758.

13. Auer L, Deinsberger W, Niederkorn K, Gell G, Kleinert R, Schneider G, Holzer P, Bone G, Mokry M, Körner E, et al. Endoscopic surgery versus medical treatment for spontaneous intracerebral hematoma: a randomized study. J Neurosurg 1989 Apr;70(4):530-535.

14. Samprón N, Mendia A, Azkarate B, Alberdi F, Arrazola M, Urculo E. Early mortality in spontaneous supratentorial intracerebral haemorrhage. Neurocirugia (Astur) 2010 Apr;21(2):93-98.

15. Schwarz S, Jauss M, Krieger D, Dörfler A, Albert F, Hacke W. Haematoma evacuation does not improve outcome in spontaneous supratentorial intracerebral haemorrhage: a casecontrol study. Acta Neurochir (Wien) 1997;139(10):897-904.

16. Zuccarello M, Brott T, Derex L, Kothari R, Sauerbeck L, Tew J, Van Loveren H, Yeh HS, Tomsick T, Pancioli A, et al. Early surgical treatment for supratentorial intracerebral hemorrhage: a randomized feasibility study. Stroke 1999 Sep;30(9):1833-9.

17. Singh TG, Ghalige HS, Karthik K, Abhilash S, Devi SR, Singh M, Kishore S, Berma D, Prasanna Kumar N. Primary supratentorial haemorrhage - surgery or no surgery in an Indian setup. J Clin Diagn Res 2014 Sep;8(9):NC01-NC03.

18. Raihan MZ, Rashid MH, Syed MA, Sarkar MH. Factors influencing the surgical outcome of spontaneous intracerebral haematoma. Mymensingh Med J 2009 Jul;18(2):245-249. 